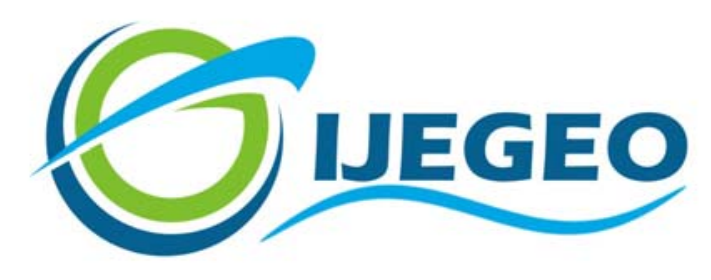

International Journal of Environment and Geoinformatics (IJEGEO) is an international, multidisciplinary, peer reviewed, open access journal.

\title{
Determination of Orthometric Height Using GNSS and EGM Data: A Scenario of The Federal University of Technology Akure
}

\section{Tata HERBERT, Raufu Ibrahim OLATUNJI}

\author{
Chief in Editor \\ Prof. Dr. Cem Gazioğlu \\ Co-Editors \\ Prof. Dr. Dursun Zafer Şeker, Prof. Dr. Şinasi Kaya, \\ Prof. Dr. Ayşegül Tanık and Assist. Prof. Dr. Volkan Demir
}

Editorial Committee (January 2021)

\begin{abstract}
Assoc. Prof. Dr. Abdullah Aksu (TR), Assit. Prof. Dr. Uğur Algancı (TR), Prof. Dr. Bedri Alpar (TR), Assoc. Prof. Dr. Aslı Aslan (US), Prof. Dr. Levent Bat (TR), Prof. Dr. Paul Bates (UK), İrşad Bayırhan (TR), Prof. Dr. Bülent Bayram (TR), Prof. Dr. Luis M. Botana (ES), Prof. Dr. Nuray Çağlar (TR), Prof. Dr. Sukanta Dash (IN), Dr. Soofia T. Elias (UK), Prof. Dr. A. Evren Erginal (TR), Assoc. Prof. Dr. Cüneyt Erenoğlu (TR), Dr. Dieter Fritsch (DE), Prof. Dr. Çiğdem Göksel (TR), Prof.Dr. Lena Halounova (CZ), Prof. Dr. Manik Kalubarme (IN), Dr. Hakan Kaya (TR), Assist. Prof. Dr. Serkan Kükrer (TR), Assoc. Prof. Dr. Maged Marghany (MY), Prof. Dr. Michael Meadows (ZA), Prof. Dr. Nebiye Musaoğlu (TR), Prof. Dr. Masafumi Nakagawa (JP), Prof. Dr. Hasan Özdemir (TR), Prof. Dr. Chryssy Potsiou (GR), Prof. Dr. Erol Sarı (TR), Prof. Dr. Maria Paradiso (IT), Prof. Dr. Petros Patias (GR), Prof. Dr. Elif Sertel (TR), Prof. Dr. Nüket Sivri (TR), Prof. Dr. Füsun Balık Şanlı (TR), Prof. Dr. Uğur Şanlı (TR), Duygu Ülker (TR), Prof. Dr. Seyfettin Taş (TR), Assoc. Prof. Dr. Ömer Suat Taşkın (TR), Assist. Prof. Dr. Tuba Ünsal (TR), Dr. Manousos Valyrakis (UK), Dr. İnese Varna (LV), Dr. Petra Visser (NL), Prof. Dr. Selma Ünlü (TR), Assoc. Prof. Dr. Oral Yağcı (TR), Prof. Dr. Murat Yakar (TR), Assoc. Prof. Dr. İ. Noyan Yılmaz (AU); Assit. Prof. Dr. Sibel Zeki (TR)
\end{abstract}

Abstracting and Indexing: TR DIZIN, DOAJ, Index Copernicus, OAJ, Scientific Indexing Services, International Scientific Indexing, Journal Factor, Google Scholar, Ulrich's Periodicals Directory, WorldCat, DRJI, ResearchBib, SOBIAD 


\title{
Research Article
}

\section{Determination of Orthometric Height Using GNSS and EGM Data: A Scenario of The Federal University of Technology Akure}

\author{
Tata Herbert* iD , Raufu Ibrahim Olatunji iD \\ Department of Surveying and Geoinformatics, Federal University of Technology Akure, PMB 704, Nigeria.
}

E-mail: htata@futa.edu.ng

Received: 23 Sept 2020

Accepted: 03 Nov 2020

How to cite: Herbert and Olatunji (2021). Determination of Orthometric Height Using GNSS and EGM Data: A Scenario of The Federal University of Technology Akure. International Journal of Environment and Geoinformatics (IJEGEO), 8(1):100-105. doi: 10.30897/ ijegeo.754808

\begin{abstract}
System (GPS) has modernized geodetic surveying in providing horizontal and vertical positions of points with a sub-meter level of accuracy over the reference ellipsoid. The GPS gives ellipsoidal heights which makes the conversion of the heights to orthometric heights possible by incorporating a geoid model. The conventional method of determining orthometric height is tedious, timeconsuming, and labour intensive. This study entails the determination of orthometric height using GNSS and EGM data. A total of forty-nine (49) stations selected within the study area were occupied for GPS observation using South DGPS instrument in static mode for the position and ellipsoidal height determination. The geoidal height values of the GPS derived data were computed using GeoidEval utility software with reference to three different EGMs (EGM2008, EGM96 and EGM84). In order to determine the orthometric heights of the selected stations, the difference between the EGM geoidal height values $\left(\mathrm{N}_{\mathrm{EGM}}\right)$ and the ellipsoidal heights were computed. The results show that the orthometric height obtained with respect to EGM2008 gives better results with a standard deviation of $9.530 \mathrm{~m}$ and a standard error of $1.361 \mathrm{~m}$. The study reveals that the use of GNSS and EGM data for orthometric height determination is less expensive, less tedious, accurate and time-saving compared to the conventional approach of geodetic and spirit levelling.
\end{abstract}

Keywords: Orthometric Height, GNSS, EGM, Geoidal Height Introduction

The difference in elevation between points on the Earth's surface is traditionally obtained through spirit levelling (and its variant such as trigonometric, barometric levelling, etc.), for over a century and the vertical control needs of the geodetic, cartographic, surveying, oceanographic and engineering communities have been well served by this technique (Featherstone, 2008). Due to the nature and practical limitations of spirit levelling most vertical control points are located in valleys and along roads/railways, which restrict the spatial resolution of control networks and confines the representation of the actual terrain (Featherstone and Dentith, 2008). As a result, most countries have completely separate networks for horizontal and vertical control with few overlapping points (Featherstone, 2008). However, with the advent of satellite-based global positioning systems (GPS, GLONASS, GALILEO, BEIDOU) and spaceborne/airborne radar systems (satellite altimetry, LIDAR, SAR) the ability to obtain accurate heights at virtually any point on land or at sea has in fact been revolutionized (Misra and Enge, 2006; Büyüksalih and Gazioğlu, 2019).

The advent of the Global Navigational Satellite System (GNSS) particularly the Global Positioning System (GPS) has revolutionized geodetic surveying by providing precise horizontal and vertical locations of points of the order of sub-metres on the reference ellipsoid (e.g. the WGS 84). The vertical location is the height above the reference ellipsoid which is also regarded as ellipsoidal height (Robert et al., 2016). However, for surveying and mapping purposes, orthometric height is preferred to the ellipsoidal height because of its relationship with the ocean (water body) and earth's gravity field which makes it to be considered as natural and physically meaningful for most applications (Isioye and Musa, 2007; Aleem et al., 2016, Olaleye, 2013; Erenoğlu and Yüceses, 2019).

According to (Benjamin et al., 2017), the height of a point on the earth's surface measured along the ellipsoidal normal to the surface of the Ellipsoid is known as ellipsoidal height (h). The height of a point on the earth's surface measured along the plumbline, normal to the Geoid, to the surface of the Geoid is known as orthometric height $(\mathrm{H})$. Orthometric height coincides with the direction of gravity vector which is at all points normal to the surface of the Geoid. Orthometric height at every point, therefore, is a function of gravity at that point (Arslan and Y1lmaz2020).

The fundamental relationship, to first approximation, that binds the ellipsoidal heights obtained from Global Navigation Satellite System (GNSS) measurements and heights with respect to a vertical geodetic datum 
established from spirit-levelling and gravity data is given by (Heiskanen and Moritz, 1967)

$$
\mathrm{h}-\mathrm{H}-\mathrm{N}=0
$$

where $\mathrm{h}$, is the ellipsoidal height, $\mathrm{H}$ is the orthometric height $\mathrm{N}$ is the geoid-ellipsoid separation (also known as geoid height) measured along the ellipsoid normal to the geoid obtained from a regional gravimetric geoid model or a global geopotential model. If the geoid is above the ellipsoid, $\mathrm{N}$ is positive. If the geoid is below the ellipsoid, $\mathrm{N}$ is negative. It is important to note that the ellipsoid height $(\mathrm{h})$ and the geoid height $(\mathrm{N})$ must refer to the same reference ellipsoid for the relationship to hold. The geometrical relationship between the three geodetic surfaces is shown in Figure 1.

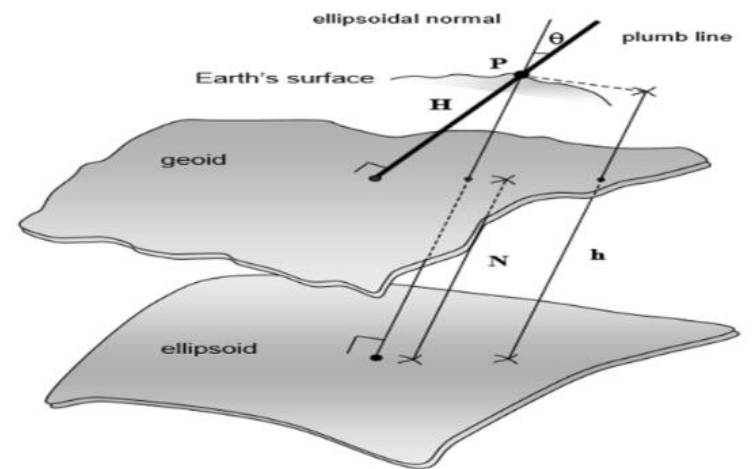

Figure 1- Relationship between the ellipsoidal, geoid and orthometric heights (Fotopoulos 2003).

The inherent appeal of this seemingly simple geometrical relationship between the three height types is based on the premise that given any two of the heights, the third can be derived through simple manipulation of Eq.1.

Conventional methods of determination of orthometric heights are differential levelling which includes Spirit

$$
V(r, \theta, \lambda)=\frac{G M}{r}\left\{1+\sum_{n-1}^{N \max } \sum_{m=0}^{l}\left(\frac{\alpha}{r}\right)^{l}\left(\bar{C}_{n m} \cos _{m \lambda}+\bar{S}_{n m} \sin _{m \lambda}\right) \bar{P}_{n m}(\cos \theta)\right\}
$$

The expression for computing geoid undulation $(\mathrm{N})$ from such a set of spherical harmonic coefficients is

$$
N e g m=\frac{G M}{r \gamma} \sum_{n=2}^{n m a x}\left(\frac{\operatorname{araf}}{r}\right) \sum_{m=0}^{n}(\bar{C} n m \cos m \lambda+\bar{S} n m \sin m \lambda) \bar{P} n m(\cos \theta)
$$

Where, GM is the product of the universal gravitational constant and mass of the earth, $r$ is the geometric distance between the earth centre of the earth and the computation point, araf is a sealing parameter associated with a particular GGM, $\bar{C}$ and $\bar{S}$ are fully normalized spherical harmonic coefficients after reduction by the even zonal harmonic of the reference ellipsoid and nmax is the finite maximum degree of a GGM $\bar{P} n m$ is the fully normalized associated Legendre function for degree $n$ and order $\mathrm{m}, \theta$ and $\lambda$ are the geodetic latitude and longitude.

The conventional approach of determining orthometric heights of points using a spirit level is time-consuming, labour intensive and tedious. An approach such as Gravimetric, GPS/leveling, Earth Gravity Models now employed to acquire orthometric height are less tedious, accurate, time-saving and also cover a large extent of the study area. This paper focuses on the determination of orthometric heights using GNSS and EGM data. In this study, orthometric height of points in Federal University of Technology, Akure, Ondo State were determined through the determination of ellipsoidal coordinates of selected points using DGPS observations on static mode, determining the geoidal height using GeoidEval utility calculator software and assessing the computed orthometric heights with respect to different Earth Gravitational Models (EGMs) over the study area. 


\section{Study Area}

The selected study area is the Federal University of Technology, Akure, the main campus in Akure South Local Government Area of Ondo State, Nigeria. The
University lies between latitude $7^{\circ} 18^{\prime} 03^{\prime \prime} N$ to $7^{\circ} 18^{\prime} 06^{\prime \prime}$ $\mathrm{N}$ and longitude $5^{\circ} 08^{\prime} 02^{\prime \prime} \mathrm{E}$ to $5^{\circ} 08^{\prime} 05^{\prime \prime} \mathrm{E}$. It is located along Akure-Ilesa expressway, with Awule and Ibule as the neighbouring villages. Figure 2 below shows the study area location.

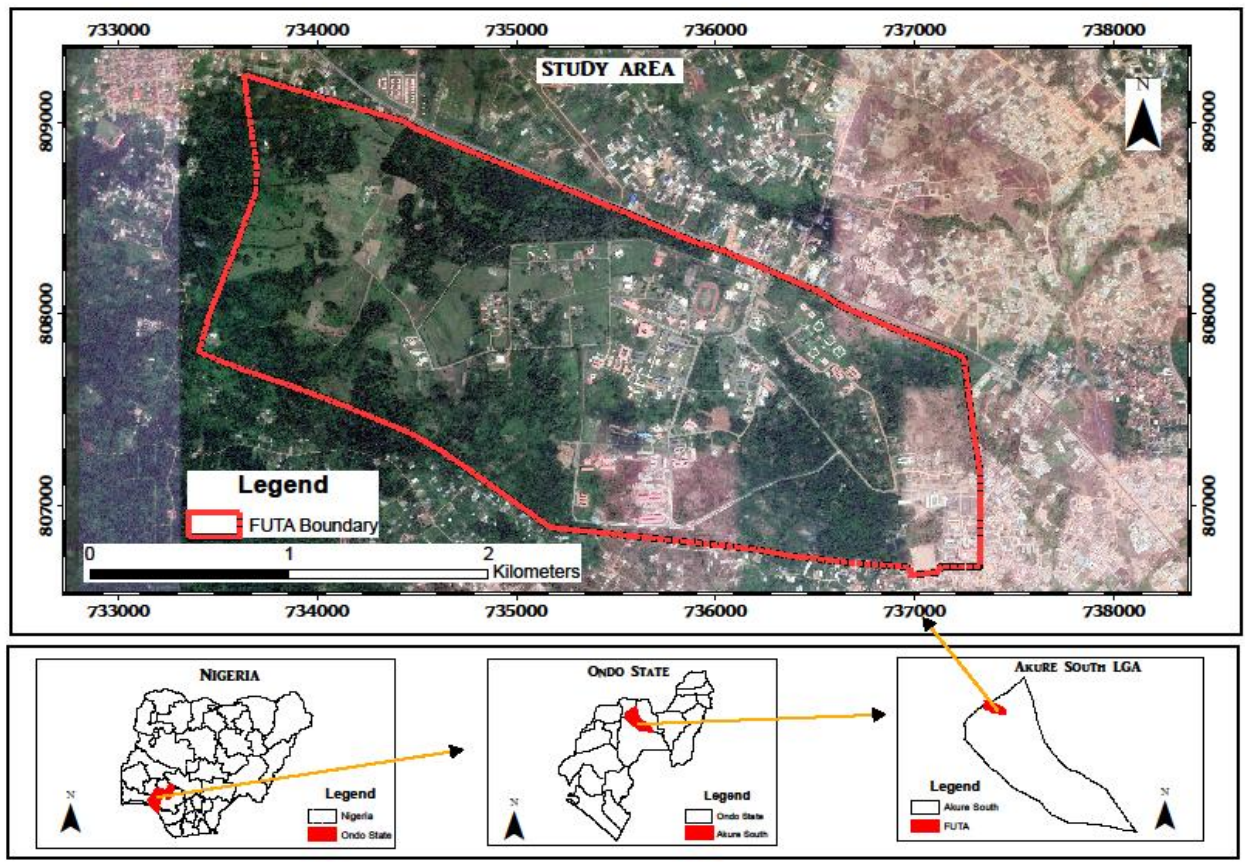

Figure 2. Administrative Map of the Study Area

\section{Materials and Method Data Acquisition}

A total of forty-nine (49) existing control points within the study area were used for GPS observation. South Differential Global Positioning Systems (DGPS) with its complete accessories was used in static mode for the determination of the positions and ellipsoidal heights of each of the points. The geoidal height values of the GPS derived data were computed using GeoidEval utility software with reference to three different Earth Gravitational Models (EGM2008, EGM96 and EGM84).

\section{Data Processing}

The raw differential GPS data were processed using South GNSS Processor software to obtained the 3Dimensional coordinates $(\mathrm{X}, \mathrm{Y}, \mathrm{Z})$ of the points which were later converted to geographic coordinates (latitudes and longitudes) and inputted into GeoidEval utility software to obtained the geoidal undulations. More information on GeoidEval utility can be found at URL1.

\section{Determination of Orthometric Heights with Reference to Various EGMs}

GeoidEval utility software computes the height of the geoid above the WGS84 ellipsoid using interpolation in a grid of values for the earth gravity models, EGM84, EGM96 or EGM2008. The ellipsoidal height was obtained through GPS observations. Hence the orthometric heights of the forty-nine (49) stations were determined by computing the differences between the ellipsoidal heights $(\mathrm{h})$ and the geoidal heights $(\mathrm{N})$. This is expressed mathematically as;

$$
\mathrm{H}=\mathrm{h}_{\mathrm{GNSS}}-\mathrm{N}_{\mathrm{EGM}}
$$

\section{Standard deviation and Standard error}

In this study, the standard deviation of the orthometric heights values for each set of EGM values was estimated using a statistical analysis tool on the Microsoft Excel Spreadsheet. The tool works on the principle that lets the sample be $\mathrm{x}$ and the sample size be $\mathrm{n}$. The standard deviation is given by equation (3) below.

$$
S=\sqrt{\frac{\sum(X-\bar{X})^{2}}{n-1}}
$$

While the standard error is estimated as $\mathrm{SE}=\mathrm{S} / \sqrt{ } \mathrm{n}$

\section{Results and Discussion}

The results presented in this study are the Universal Transverse Mercator (UTM) coordinates and ellipsoidal heights of all stations which were determined through GPS observations in the study area and post-processed using South GNSS processing software (Table 1), the geoidal undulation values, the ellipsoidal heights and their respective orthometric heights determined from GPS data with reference to different Earth Gravity Models (EGMs) in meters (Table 2). The standard deviation and standard error computed from each set of orthometric heights values determined with respect to each Earth Gravity Model are shown in Table 3. The geographical and UTM coordinates of all the selected stations in the study area are shown in Table 4. The 3Dimensional surface model of the orthometric heights 
values with respect to different earth gravity models is shown in Figure 3(a), 4(a) and 5(a) while the contour maps plotted from the orthometric heights values of
EGM84, EGM96 and EGM2008 models is shown in Figure 3(b), 4(b) and 5(b) respectively.

Table 1.

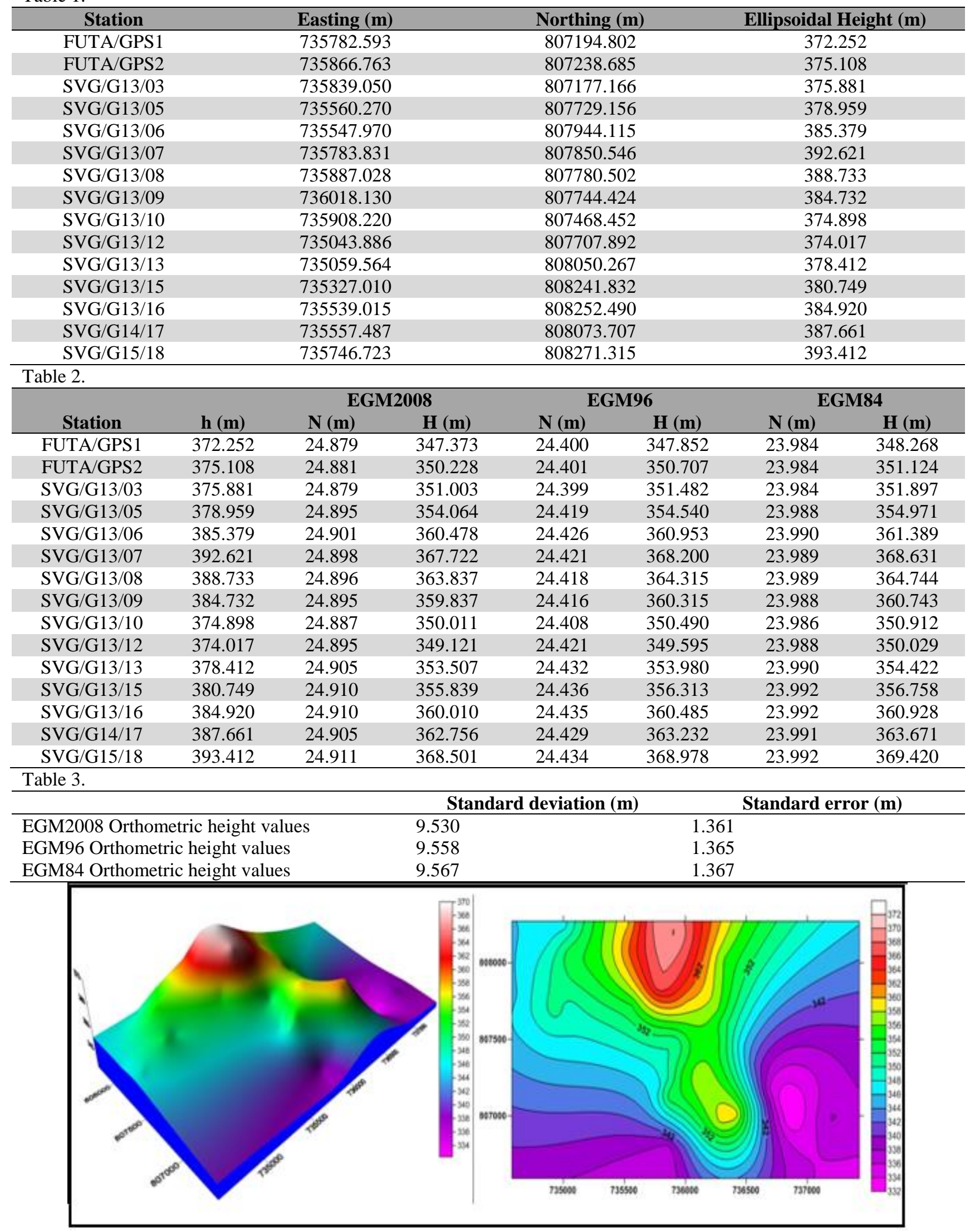

Figure 3. 3D model of EGM 2008 orthometric height and contour plot. 


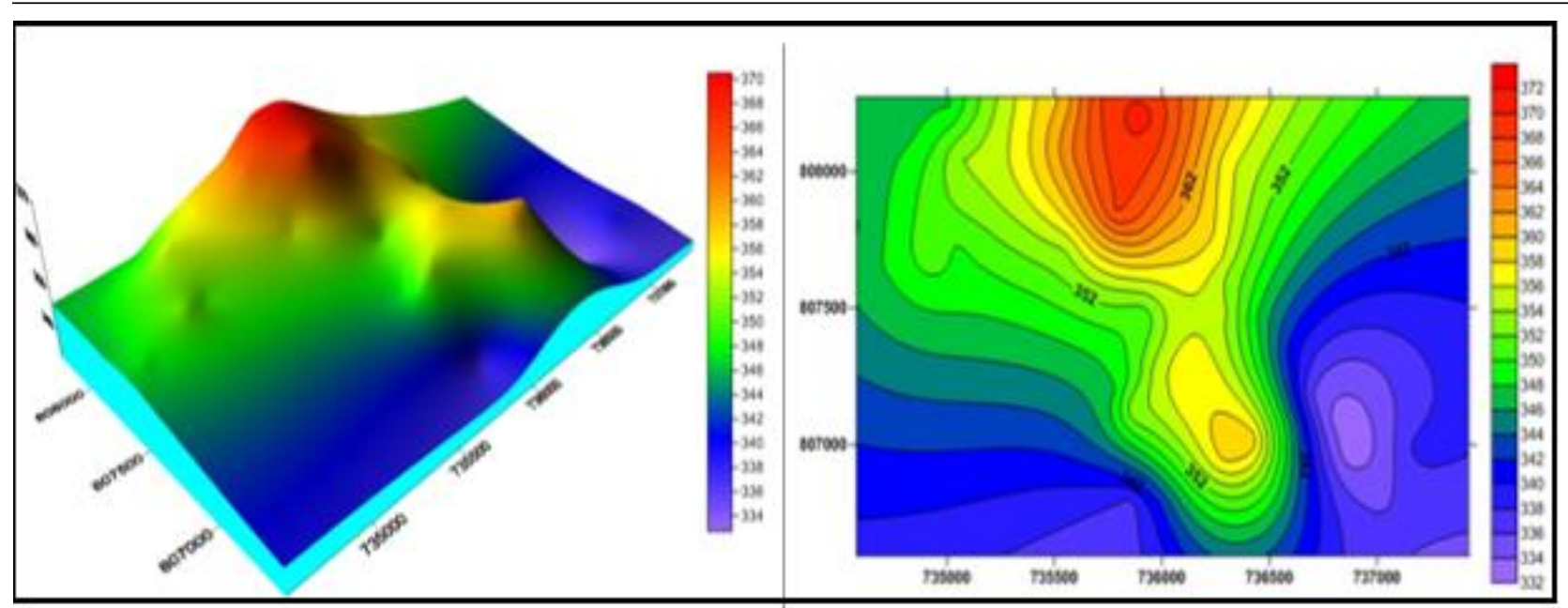

Figure 4. 3D model of EGM 96 orthometric height and contour plot

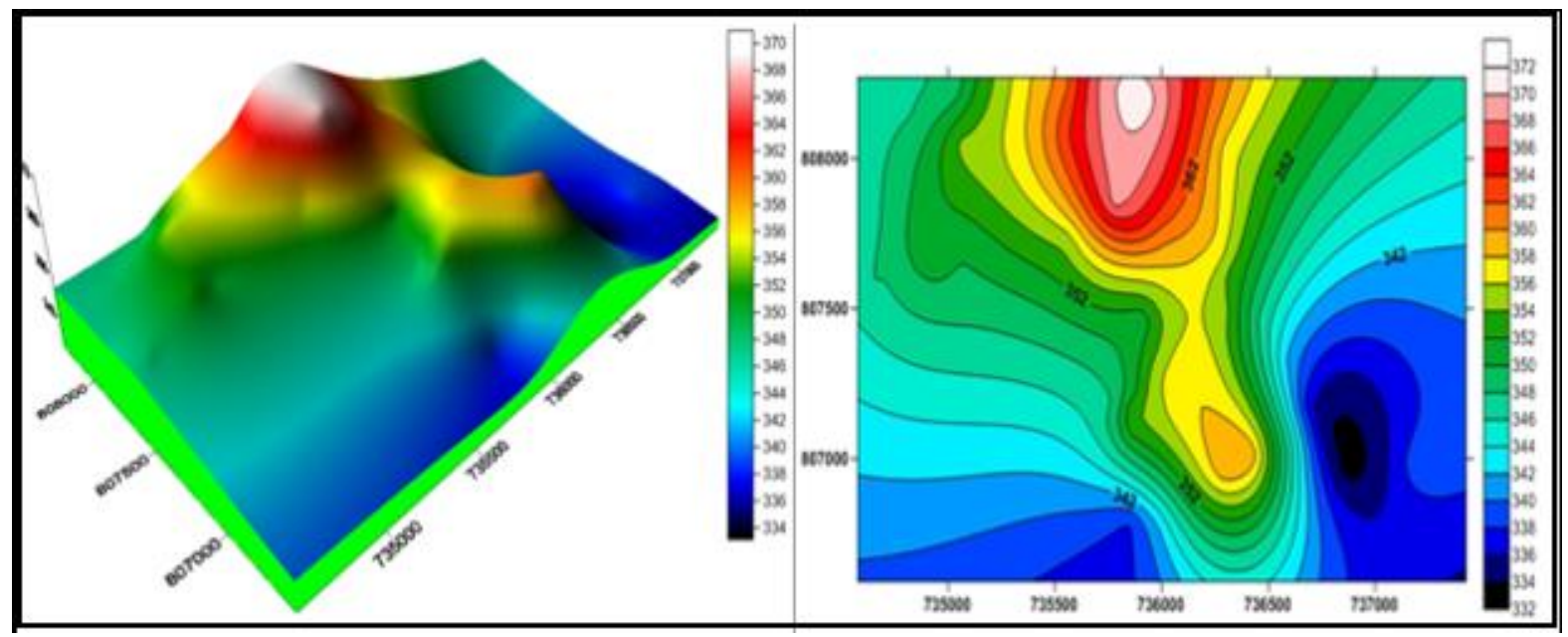

Figure 5. 3D model of EGM 84 orthometric height and contour plot.

\section{Discussion of Results}

The results obtained shows that orthometric heights derived through EGM2008 geoidal heights gives better accuracy with standard deviation of $9.530 \mathrm{~m}$ and standard error of $1.361 \mathrm{~m}$ which can be attributed to the addition of spherical harmonic co-efficient to the geoidal height values extended to degree 2190 and order 2159 which becomes most suitable gravity model for the determination of orthometric height of selected points within the study area. The maximum error was provided by EGM84 with a standard deviation of $9.567 \mathrm{~m}$ and a standard error of $1.367 \mathrm{~m}$ respectively. Also, the obtained results depict that, there is a notable improvement in using EGM2008 geoidal height values compared to EGM96 and EGM84. Figure 3, 4 and 5 are contour plots and 3D surface model plotted from orthometric height values of different Earth Gravity Models of different degrees and order of accuracy and contour map plotted using orthometric height determined from the difference between geoidal height data (EGM2008, EGM96 and EGM84) and ellipsoidal height data obtained through GPS observations as shown in Table 2. Kriging method was adopted in plotting the 3D and contour maps using Surfer 11 software. The maximum and minimum contour values are $372 \mathrm{~m}$ and $332 \mathrm{~m}$ at the $2 \mathrm{~m}$ grid interval.

\section{Conclusions}

This study has attempted the derivation of orthometric height using GNSS and Earth Gravity Model (EGM) data. The ellipsoidal heights were obtained from the processed GPS observations using South GNSS Processor and the geoidal heights were obtained using GeoidEval utility software. The orthometric heights were derived by computing the difference between geoidal heights obtained from the EGMs and the ellipsoidal heights. Analysis of results obtained shows that orthometric heights obtained through EGM2008 is more accurate with the standard deviation of $9.530 \mathrm{~m}$ and standard error of $1.361 \mathrm{~m}$. Significant differences were observed between the orthometric height values obtained with respect to EGM84 and EGM2008. The average difference between EGM84 and EGM2008 orthometric height values is about $1 \mathrm{~m}$ while the average difference between EGM96 and EGM2008 orthometric height values is $0.5 \mathrm{~m}$ which can be attributed to the refinement of the earth gravity model to higher degree and order of accuracy. The use of GNSS and EGM data for orthometric height determination has proven to be vibrant compared to the labour intensive, tedious and time-consuming conventional method of geodetic levelling and spirit levelling approach. 


\section{References}

Aleem, K.F., Adesoye, A.A., Bankole, A.L. (2016). Practical Determination of Geoidal Undulation and Geoidal Map of Part of Mubi, Adamawa State, Nigeria. International Journal of Engineering Research and Technology (IJERT). 4 (5): 2278-0181.

Arslan, O, Y1lmaz, P. (2020). Evaluating the Geometric Accuracy of Large Scale Digital Orthophotos Produced from Aerial Photography. International Journal of Environment and Geoinformatics, 7(3), 265-271.doi.10.30897/ijegeo.729587.

Benjamin J.B., Ahmed M., Matapa J.I. (2017). Assessment of Geoidal Undulation Values Computed with Reference to Different Earth Gravity Models. IOSR Journal of Environmental Science, Toxicology and Food Technology (IOSR-JESTFT), 11 (6), 64-72.

Büyüksalih, İ., Gazioğlu, C. (2019). New Approach in Integrated Basin Modelling: Melen Airborne LIDAR, International Journal of Environment and Geoinformatics, 6(1), 22-32.doi. 10.30897/ijegeo.530272.

Erenoğlu, R, Yüceses, O. (2019). Deformation Analysis by Geomatic and Geotechnical Methods in Highway Tunnels. International Journal of Environment and Geoinformatics, 6(2), 163-171. doi. 10. 30897 /ijegeo.540837.

Featherstone, W.E., (2008). GNSS-based Heighting in Australia: Current Emerging and Future Issues. Spatial Science, 53(2), 115-133.

Featherstone, W.E., Dentith, M.C., and Kirby, J.F. (1998). Strategies for Accurate Determination of Orthometric Heights from GPS, Survey Review, 34 (267), 278-296.

Fotopoulus, G. (2003). An Analysis on the Optimal Combination of Geoid, Orthometric and Ellipsoidal Height Data. PhD Thesis, Department of Geomatics Engineering, University of Calgary. UCGE Reports No. 20185.

Heiskanen, W.A., Moritz, H. (1967). Physical Geodesy, Freeman and Company, San Francisco, 364 pages.

Isioye, O. A., Musa, A. (2007). The use of geodetic levelling for crustal movement and deformation studies: A 30-year case study in Ahmadu Bello University Zaria. The Information Manager, 7(2), 2839.

Kemboi K. E., Odera P. A. (2016). Estimation of Orthometric Height Using EGM2008 and GPS Over Nairobi County and Its Environs. Jomo Kenyatta University of Agriculture and Technology, Nairobi, Kenya 17 (2), 118-131.

Misra P., Enge P. (2006). Global Positioning System Signals, Measurements, and Performance (2nd edition), Ganga-Jamuna Press, Massachusetts.

Olaleye, J.B., Badejo, O.T., Olusina, J.O., Aleem, K.F. (2013). Rectangular 'Satlevel' Model for Quick Determination of Geoid: A Case Study of Lagos State of Nigeria. Journal of Emerging Trends in Engineering and Applied Sciences (JETEAS) 4(5), 699-706.

Opaluwa Y. D., Adejare Q. A. (2011). Derivation of Orthometric Heights from GPS Measured Heights Using Geometrical Technique and EGM 96 Model.
FUTY Journal of the Environment; 5(1), 1-20 DOI: 10.4314/fje.v5i1.63477.

Robert, R., Sujoy K.J., Rabindra, K.D., Dilip, K.P. (2016). Evaluation of Orthometric Heights from GPS Survey using a Geoid Model - A Case Study for Madang, Papua New Guinea. International Journal of Advancements in Research \& Technology, 5 (5), 916.

URL1: https://geographiclib.sourceforge.in. 